\title{
Active-Reactive Power Control of Grid-Tied Solar Energy Systems, Using Multi-Parameter Band Control for Grid Voltage Regulation
}

\section{Mustafa Tekin*, Mustafa Sekkeli}

University of Kahramanmaras Sutcu Imam, Faculty of Engineering and Architecture, Department of Electrical-Electronic Engineering, Kahramanmaras, Turkey, email: mustafatekin@ksu.edu.tr,msekkeli@ksu.edu.tr

Abstract: One of the most studied and funded renewable energy sources is solar energy, all over the world. Solar panels are used to obtain electrical energy from the sun. They should be used effectively due to their expensive structure and challenging installation. However, as the sun light only reaches to the earth during daylight hours, solar systems cannot generate active power during the night, or in cases where daylight is not enough, the whole power capacity of the solar inverters have not been used. In this study; it was shown that in addition to the active power generation during the daytime hours, the solar systems were able to generate reactive power with the remaining capacity of the inverter. Thereby adjusting the grid voltage was provided by the solar system's reactive power control. Designed solar system generates completely reactive power at nights. Thus, the efficiency of the solar systems has been increased by ensuring that the solar systems have used to keep the grid voltage within the values, which stated in the standards, by producing reactive power as well as active power. Matlab/Simulink was used to model the system when using hysteresis band method for system control.

Keywords: power grids; reactive power control; renewable energy sources; solar system; voltage control

\section{Introduction}

Daily, the development of technology and the increase in the human population increases the demand for electrical energy. People have used traditional sources of energy, such as, coal, natural gas and oil for years, to meet electricity demands. Today, however, these resources are not capable in meeting the energy needs, moreover, using these resources pollutes the environment and depletes its reserves. Therefore, over the last twenty years, renewable energy sources which are solar, wind, wave, geothermal and biogas have become very popular and investments have focused on these resources. One of the most popular and most 
important among these renewable sources is solar energy, because of its simple and enduring structure. Photons from the sun have been converted into electrical energy through photovoltaic panels. The fact that used photovoltaic panels and the inverters are not cheap enough yet, emphasize the necessity of using these systems as efficiently as possible. The biggest disadvantages of using photovoltaic panels are that they do not generate at night due to the lack of sunlight on the earth and it generates an unstable amount of energy differ with the changing sunlight conditions during the day. These disadvantages can be eliminated by ensuring that the inverters used in solar systems can regulate voltage by producing reactive power at night with all their capacities and they can generate reactive power along with active power during the daytime, through the inverter's remaining capacity. Scientists have been researching the possibilities of using the full capacity of the inverters used in systems. Because they are completely non-functional at night and not employed at full capacity during the day. Some relavent current studies are listed below.

$Q / V$ control was performed to prevent the voltage oscillations caused by the photovoltaic systems which connected to the grid in [1]. In [2], the authors developed a rapid power flow response by developing an algorithm that generates a reference current. In [3], The voltage control of the busbar at the end of the line, which was selected as the critical busbar in the grid where many PhotoVoltaic (PV) systems were connected, was made by using reactive power and necessary control technique. It was performed reactive power control of a single phase, transformerless, grid connected solar inverter by [4]. In [5], voltage fluctuations in the grid due to solar systems were discussed and this problem was solved by reactive power control. In [6], the unnecessary switching of the On-Line Tap Changer (OLTC) was prevented by ensuring that the OLTC, which was present in the grid and PV system were working compatibly with each other. Using the sliding mode control, the inverter in the PV system was provided to generate useful reactive power in the study [7]. In article [8], the reactive power at the inverter output was controlled by the linear decision rules method. In [9] and [10], the active and reactive power control of the inverter was realized. In [11], to prevent the voltage rise at the grid connection point of the PV systems, the reactive power adjusted through the inverter's reactive current control. In article [12], the reactive power of the inverter was controlled by the Quasi Sinusoidal Waveform method. The triggering performances of the solar inverter's, used as reactive power generator, switching elements were analyzed in [13]. After the connection of the PV systems to the grid, the reverse power flow due to the supply-demand imbalance was mentioned and possible solution for the situation can be fixed with the control of $P-Q$ and $Q-V$ in [14]. In [15], the solar inverter was used as a harmonic and reactive power compensator. The active-reactive power production balance of the inverter output was controlled in [16-18]. The reactive power control of the inverter was made by reactive current control in [19]. In [20], the response of the inverter to the unexpected conditions in the grid was analyzed. In the study [21], the PV system with a battery was connected in 
parallel with the grid and the inverter of PV provided harmonic compensation to the grid using the active-reactive power control. In [22], active harmonic filtering was performed by using type- 2 fuzzy control method. The active-reactive power control of the inverter was done by the passivity-based method in the article [23], it was made by the incremental conductance method in [24]. A new relay was designed for reactive power control in [25].

In the light of all these works; the grid-connected PV system was modelled in Matlab/Simulink environment in this study. By controlling the phase angle and amplitude of the inverter voltage of this PV system, in case of the presence of the insufficient amount of sunlight or at night, it was ensured that the grid voltage was kept at optimum values with the active-reactive power production balance of the inverter. Unlike other studies in the literature, with this work, it was ensured that the inverter provides the most suitable active-reactive power response to the grid by considering the amount of radiation on the environment, the inverter power capacity and whether the grid voltage was at the critical limit values. Accordingly, a new approach to the literature has been introduced.

\section{Structure and Components of the System}

In this study; a low-voltage grid, which is connected to the three-phase solar system, was modelled. The capacity of the inverter connected to the electricity grid was selected as $1 \mathrm{kVA}$ in the Matlab model. The PV system consists of a phase lock loop (PLL), a pulse width modulation (PWM) generator, solar inverter and controller of this inverter. The system diagram was given in Figure 1.

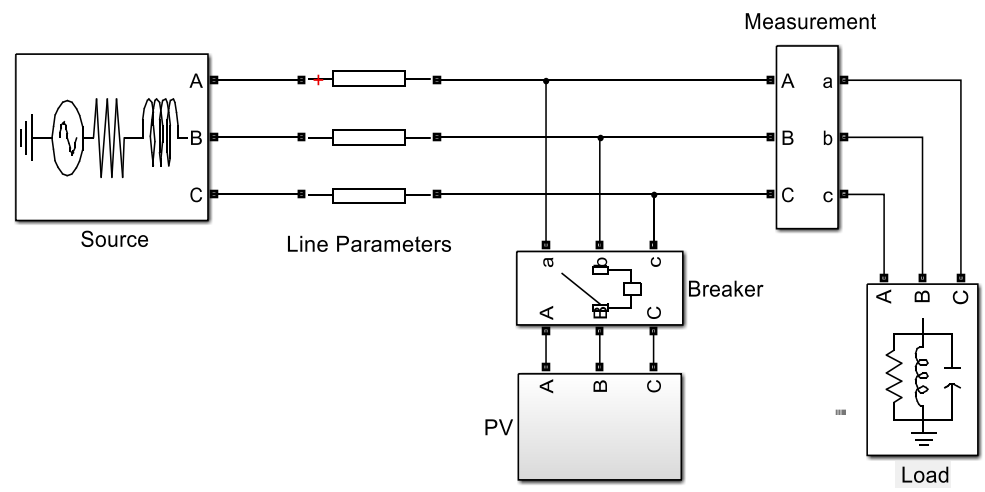

Figure 1

Power system with solar inverter 


\subsection{Solar System}

The model of the PV system was given in Figure 2. The PLL and PWM generator of the inverter were embedded in the PWM generator block. A boost type converter was used in the solar system and the inverter output was filtered as it was shown in Figure 2. Phase angle control was performed with phase controller block. There is a system in the grid and it determines the amount of radiation, the inverter capacity and the reactive power in the phase controller block.

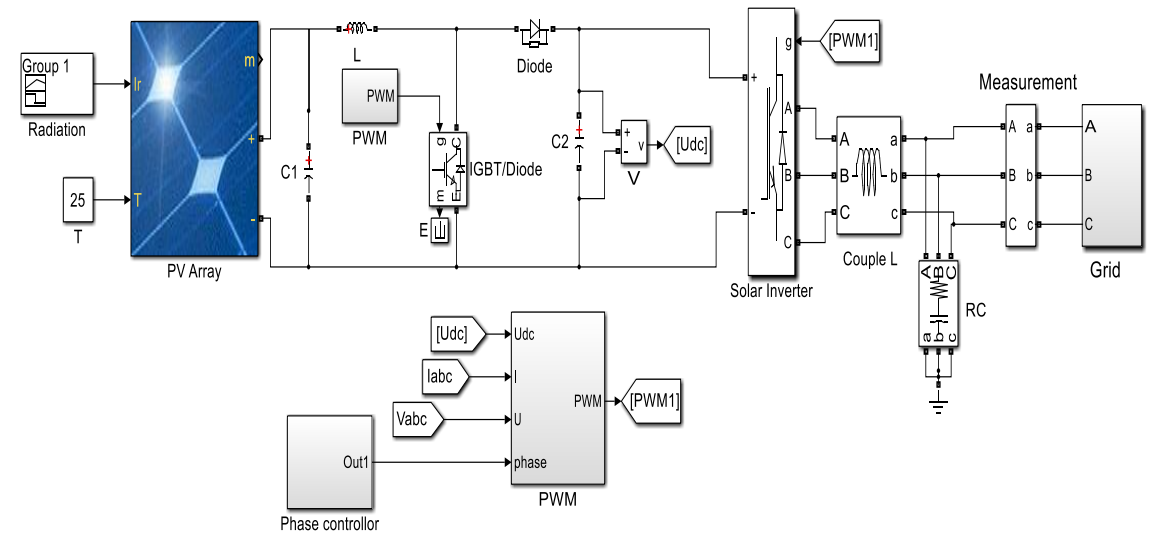

Figure 2

Solar system

\subsection{Phase Lock Loop (PLL)}

In the grid-connected solar system, PLL is the component that allows the inverter and grid voltage to synchronize with each other [26]. A PLL operates in its simplest form that the phase angle of the reference signal from the grid is determined by the phase detector. Then the obtained signal is passed through the low pass filter and entered into the voltagecontrolled oscillator so that the voltage is generated at the desired phase angle and frequency. The PLL block was shown in Figure 3.

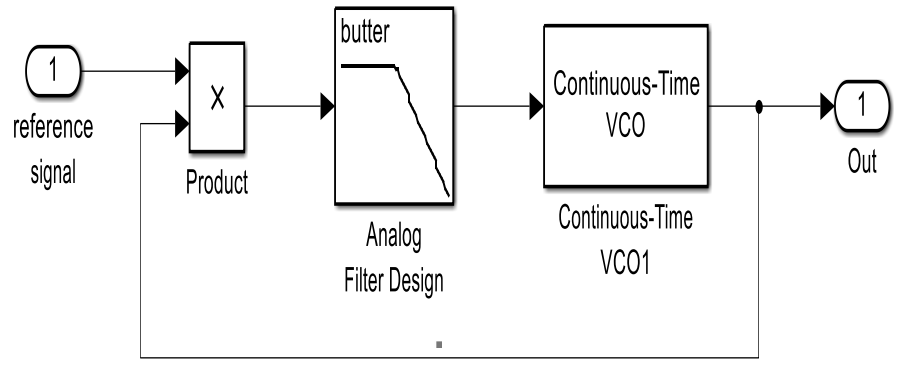

Figure 3

PLL block diagram 


\subsection{PWM Generator}

The PWM is a control element that converts analogue input to digital output ( 0 or 1). PWM technique has been used in many areas. One of the most important parameters in this technique is Duty Cycle (D) [27]. D is a variable that analyzes how long the PWM output is "on" over a period and is usually given in percentage.

The logic operation of PWM was summarized in Figure 4. According to this figure; the triangular wave has compared to the sinus wave, during the time when the sinus is greater than the triangle, the output is equal to 1 , during the time when vice versa output is equal to 0 and thus sine wave, which gives as reference, in the beginning, is converted a digital signal. In this study, PWM was used to convert the alternative voltage signal from the input to a digital signal that used to trigger the inverter switches. The basic single phase equivalent of PWM was given in Figure 5.

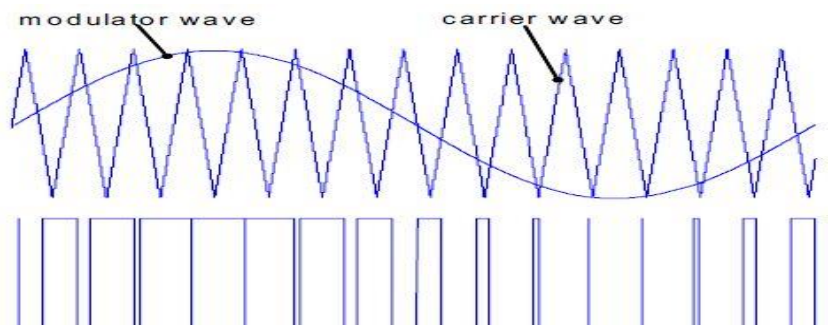

Figure 4

PWM technique [28]

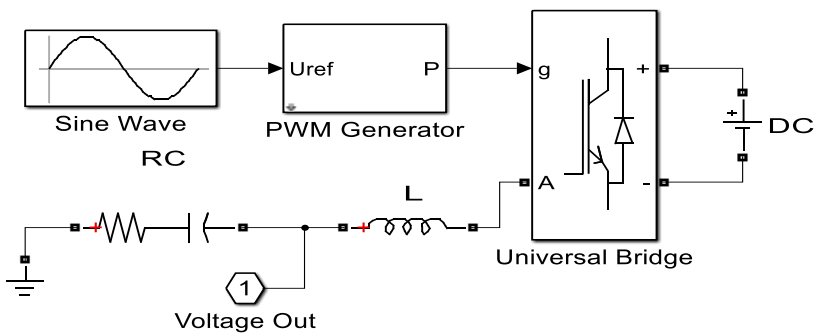

Figure 5

PWM generator block diagram

\subsection{System Parameters}

System parameters are determined as follows, the reactive power of the grid, the grid voltage, the amount of radiation in the environment and the active-reactive 
power of the solar inverter. The general power formula is given in (1), the active and reactive power of the inverter are given in (2) and (3) respectively.

$$
\begin{aligned}
& S=\sqrt{P^{2}+Q^{2}} \\
& P=V_{i} \frac{V_{s}}{2 \pi f L_{c}} \sin \theta=P_{\max } \sin \theta \\
& Q=\frac{V_{i}^{2}}{2 \pi f L_{c}}-V_{i} \frac{V_{s}}{2 \pi f L_{c}} \cos \theta
\end{aligned}
$$

In the above equations; $S$ represents the apparent power, $P$ inverter active power, $Q$ inverter reactive power, $\theta$ angle represents the phase angle between the grid voltage $V_{s}$ and the inverter voltage $V_{i}$, the $L$ coupling coil and the $f$ frequency (50 $\mathrm{Hz}$ ). In the active-reactive power control of the system, the phase angle with the inverter voltage amplitude holds an important place. Figure 6 shows that reactive power change versus the voltage change.

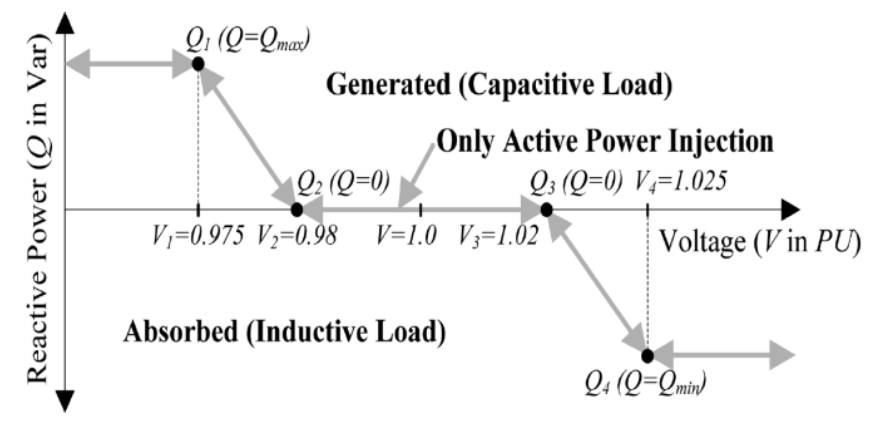

Figure 6

Reactive power-voltage change chart [30]

\section{System Control}

The parameters to be controlled in the system are the phase angle of the voltage at the output of the inverter to be connected to the grid, the amount of radiation in the environment, the reactive power of the inverter, the inverter output voltage amplitude and the grid voltage. Hysteresis band control was used to control these parameters. Hysteresis control works in case the specified parameters go beyond the limit values and return this parameter to the desired value by activating system control components. In this study, system control is done as follows; the voltage and reactive power values are continuously monitored by the sensors, the amount of radiation in the environment is also recorded. The measured voltage value is 
compared to the nominal (reference) voltage value. If the difference between these two voltages is at the limit values and the amount of radiation in the environment is maximum, the inverter continues to generate only active power. If the difference between the reference voltage and the voltage measured exceeds the limit value, the inverter generates the reactive power with all its capacity to prevent the voltage drop. If there is a difference between the reference voltage and the grid voltage but not around the limit values and if the amount of radiation is not the maximum value, the inverter generates reactive power with the remaining capacity from the active power generation, depending on the state of the reactive power in the electric grid. This is done by controlling the phase angle and amplitude of the output voltage of the inverter. If the amount of radiation is zero (night mode), the inverter can use its full capacity for reactive power generation. In the night mode, the inverter is allowed to generate reactive power according to the grid voltage condition as in daylight mode. The logical flow diagram of the system is depicted in Figure 7.

\section{Results}

In this part of the study; various scenarios were tested in the Matlab/Simulink environment in order to see if the mentioned voltage regulation operation can be done with PV in the electrical grid where a solar system is connected and thus system performance was evaluated. In these scenarios, the amount of radiation in the environment, grid voltage and change of grid reactive power were modelled and how the inverter reacted to the grid in terms of active and reactive power was evaluated.

\subsection{Case-1}

In this scenario; it was assumed that the amount of radiation in the environment was $400 \mathrm{~W} / \mathrm{m}^{2}$ and the grid voltage decrease with the grid's inductive characteristic. However, this voltage drop was considered to be within the limit values. When Figure 8 shows the reactive power of the grid, Figure 9 shows the voltage amplitude in the case of this reactive power.

In the case of an inductive load is 916 VAR in the system, it is understood that the single-phase voltage amplitude of the grid is $305.7 V$ in Figure 8 and Figure 9. In this low voltage grid with a nominal value of approximately $310 \mathrm{~V}$, there is a voltage drops approximately $4.3 \mathrm{~V}$ caused by both active and reactive loadings. The following graphs indicate that how much of this voltage drop was caused by inductive loading. 


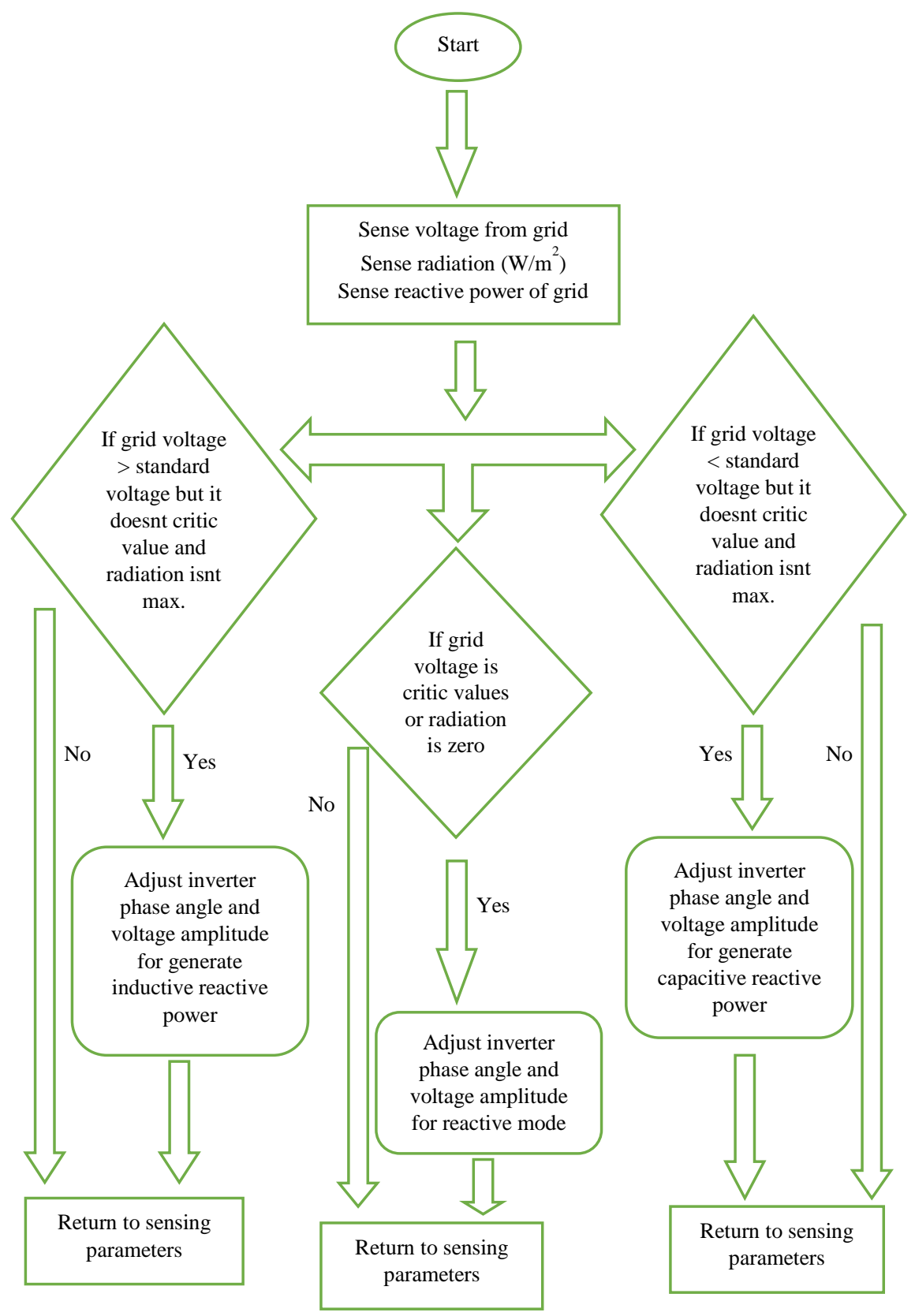

Figure 7

Block flow diagram of the system 
The active-reactive power response of the $1 \mathrm{kVA}$ solar inverter is shown in Figure 10. Figure 10 shows that the solar inverter was connected to the grid with a 1 second delay. This is due to the integration conditions required for frequency and voltage. In the $400 \mathrm{~W} / \mathrm{m}^{2}$ environment, the inverter uses it's $400 \mathrm{~W}$ capacity for active power generation, it is understood that the capacitive reactive power capacity of approximately -900 VAR of inverter was used to compensate the +900 VAR inductive reactive power where already exists in the grid.

Inverter and grid reactive powers were given together in Figure 11. From this graph, it can be seen that the inverter reacts by generating capacitive reactive power to the grid to eliminate the inductive load that exists in the grid.

It is observed in Figure 12 that the inductive reactive power is eliminated by the solar inverter and the grid voltage amplitude increases from 305.7 to 305.9 Volts. This $0.2 \mathrm{~V}$ voltage regulation is achieved with the selection of the inverter capacity as $1 \mathrm{kVA}$ and the reactive power generation in the grid according to this selection. In other words, this effect will also increase in the selection of a larger grid and inverter.

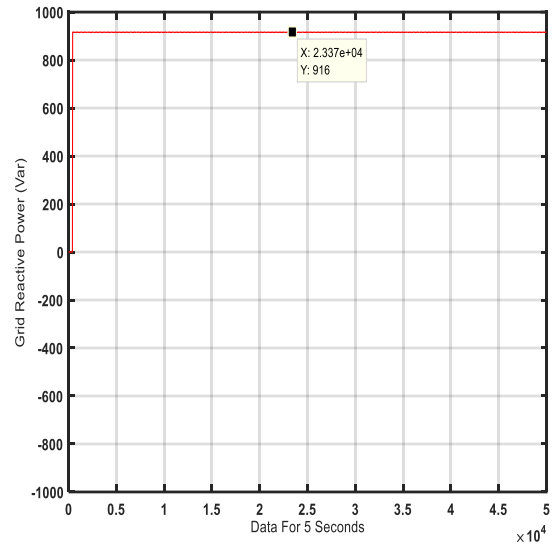

Figure 8 Inductive reactive power of grid

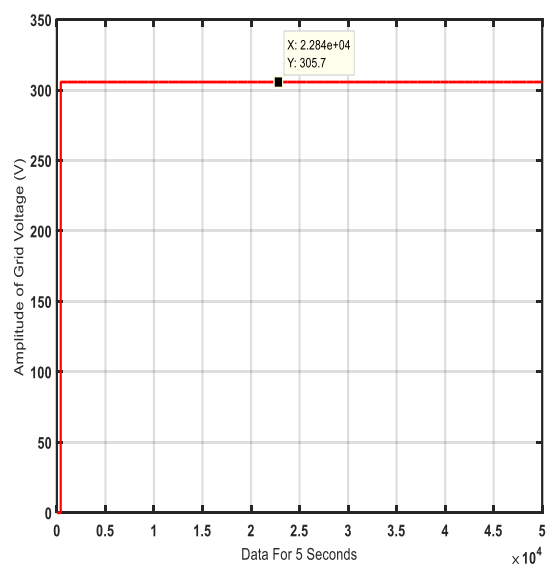

Figure 9 Grid voltage amplitude 


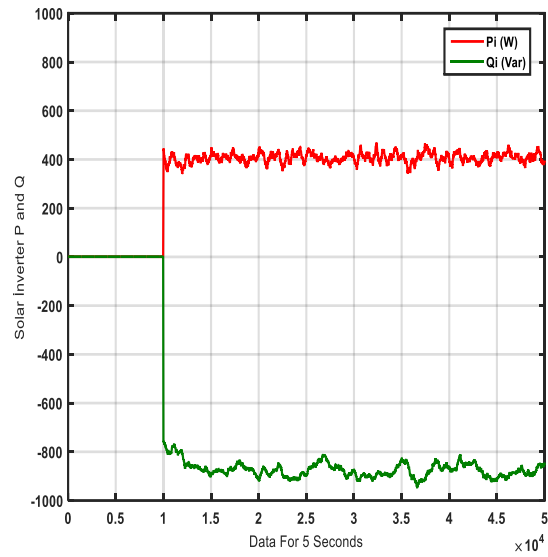

Figure 10

Active-reactive power response of inverter

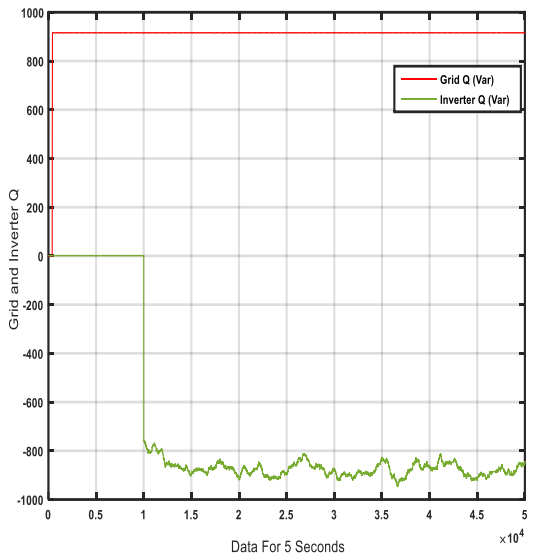

Figure 11

Grid and inverter reactive powers

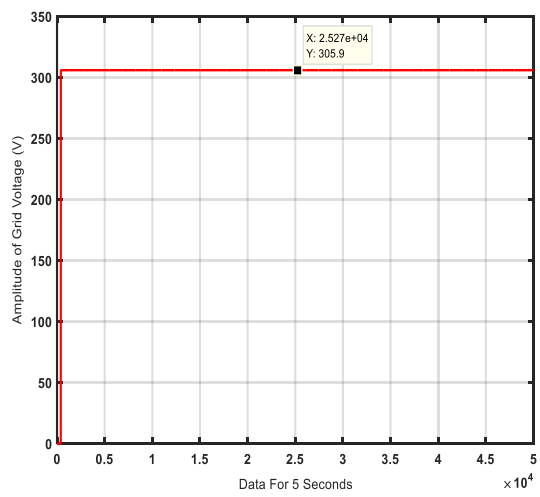

Figure 12

Regulated grid voltage

\subsection{Case-2}

In this scenario; approximately $800 \mathrm{~W} / \mathrm{m}^{2}$ of radiation amount exists in the midday and the situation where the voltage drop was close to the lower limit values (critical condition) was modelled. The system was designed to be inductive, and since the voltage drop was close to the limit value, regardless of the amount of radiation, the solar inverter used the entire power capacity for capacitive reactive power to pull the voltage higher and prevent the low voltage relays in the distribution grids from disabling the system. This means that the inverter does not generate active power notwithstanding the radiation amount. The critical value of the grid voltage amplitude and 1000 VAR inductive reactive power were given in Figure 13 and Figure 14 respectively. 


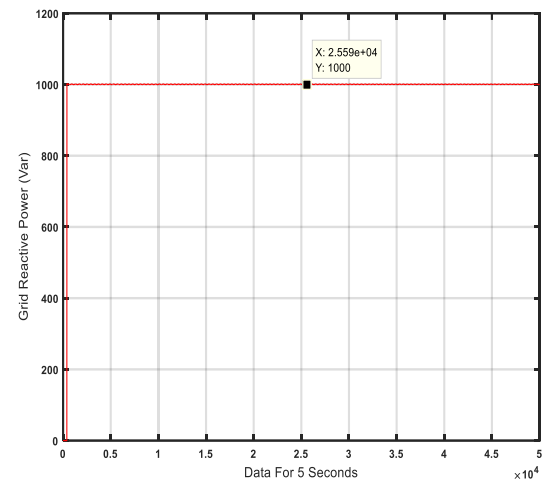

Figure 13

Inductive reactive power of grid

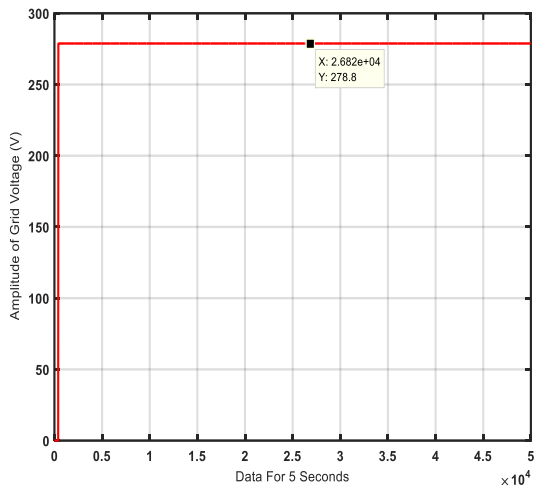

Figure 14 Grid voltage amplitude

Figure 14 shows that the grid voltage is $278.8 \mathrm{~V}$, which is the critical voltage value due to the active and reactive power supplied by the system. In this case, the response of the inverter in terms of active and reactive power generation was given in Figure 15.

As seen in Figure 15, despite the fact that radiation is maximum, the inverter has used its entire capacity to generate capacitive reactive power as the grid voltage is at critical values.

As a result of this response of the inverter, the amplitude of the grid voltage was given in Figure 16. It was understood from the voltage amplitude graph of Figure 16 that initially, when the grid voltage was about to almost disable the grid with the amplitude of 278.8 Volts, the voltage amplitude was brought to 279 Volts through the capacitive response of the inverter thus it prevented the disable of grid.

In Figure 17, the reactive power of the grid and the inverter were given at the same time and so the reactive power contribution of the inverter to the grid was seen more clearly. 


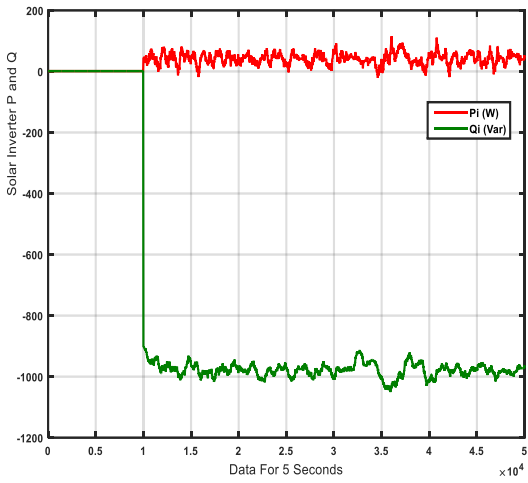

Figure 15

Active-reactive power response of inverter

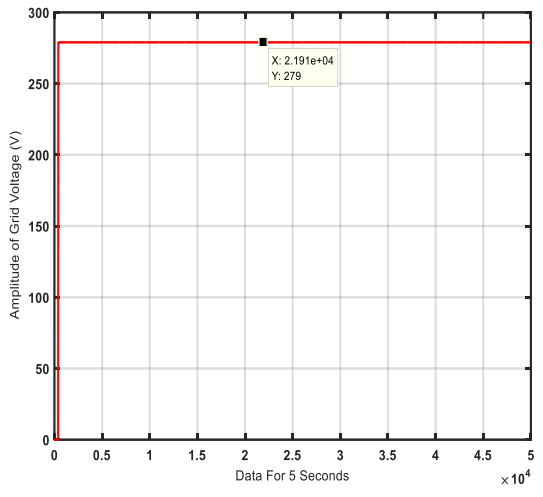

Figure 16

Regulated grid voltage

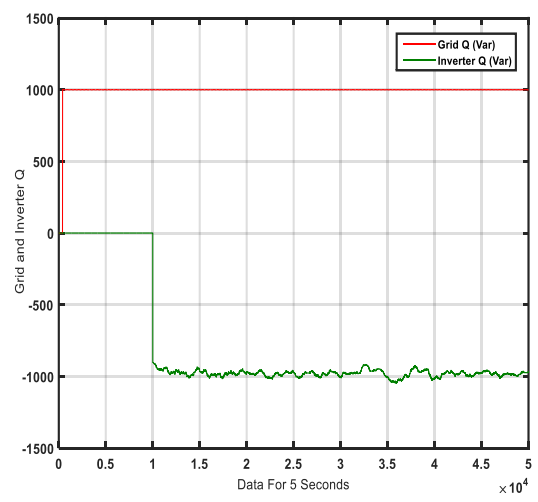

Figure 17

Grid and inverter reactive powers

\subsection{Case-3}

In this scheme of the study, it was taken into consideration that the amount of radiation is $600 \mathrm{~W} / \mathrm{m}^{2}$ and the grid has capacitive properties so that the grid voltage was increased but not critically. In this case, the response of the solar inverter and the changes in the grid voltage were evaluated. In this context, grid reactive power and grid voltage were given in Figure18 and Figure19 respectively.

Figure 18 shows that the capacitive reactive power of the grid is approximately 800 VAR. In Figure 19 the single phase voltage amplitude value is seen as 306 Volts in this grid which has capacitive character. The reaction of the solar inverter in terms of power balance was given in Figure 20. When Figure 20 is examined, it has been understood that the inverter consumes $600 \mathrm{~W}$ of capacity for active 
power generation, the remaining power capacity of it is spent on inductive reactive power generation to suppress the capacitive reactive power in the grid.

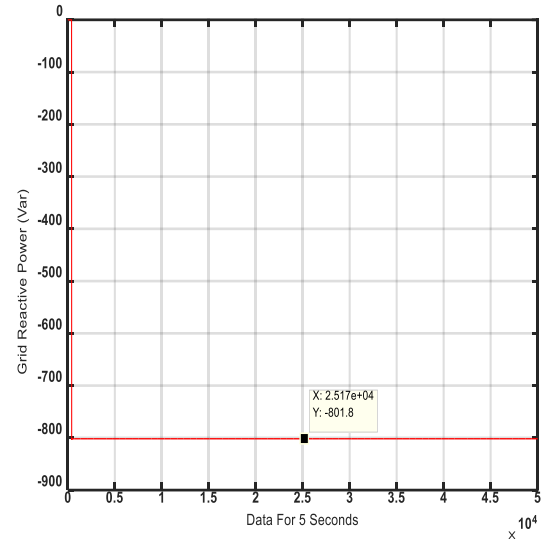

Figure 18

Capacitive reactive power of grid

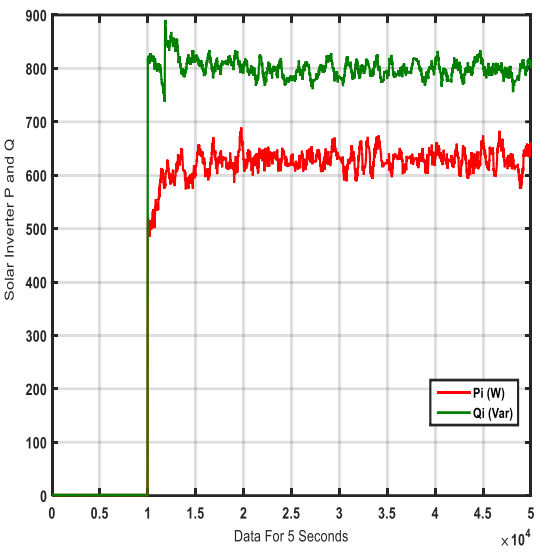

Figure 20

Active-reactive power response of inverter

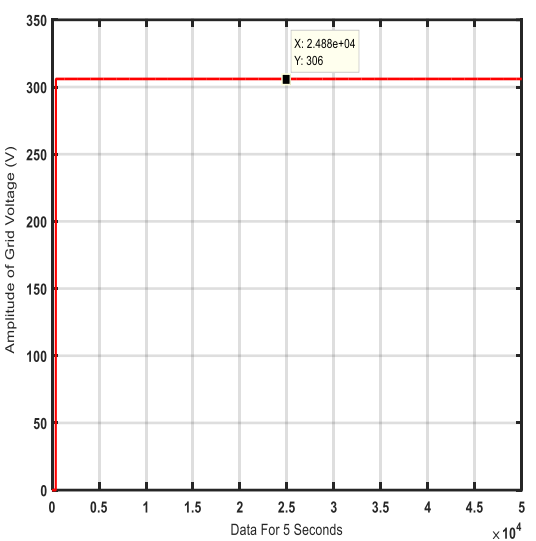

Figure 19

Grid voltage amplitude

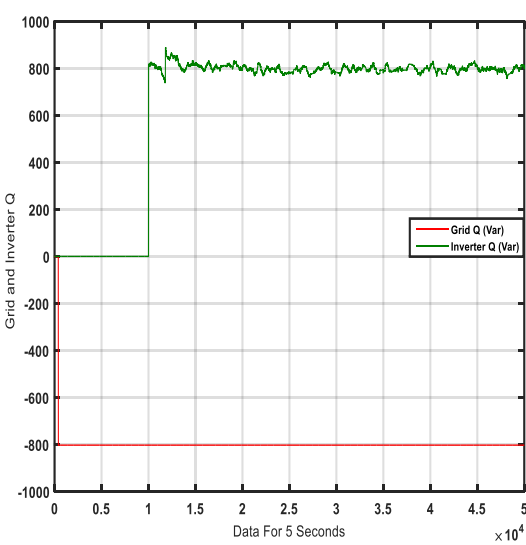

Figure 21

Grid and inverter reactive powers

The reactive power of the grid and solar inverter can be seen in the same coordinate of Figure 21. With this graph, the inductive reactive power response from the inverter to the existing capacitive reactive power in the grid can be understood more clearly.

In Figure 22, as a result of the reaction of the inverter to the grid, it is understood that the grid voltage amplitude value which is initially capacitive is decreased from $306 V$ to $305.9 V$ with only 800 VAR inverter intervention. 


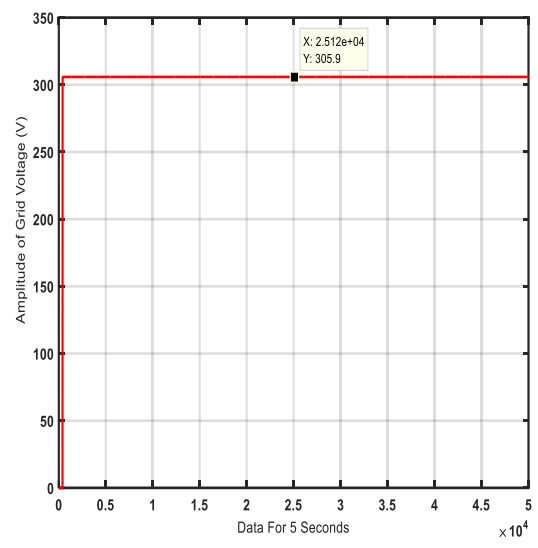

Figure 22

Regulated grid voltage

\section{Conclusions}

In this study, the aim was to improve system voltage by eliminating the reactive powers occurring in networks, by means of the opposite reactive powers and solar inverters connected to the electricity grid. The active and reactive power responses of these inverters to the grid were discussed by considering the presence of critical voltage in the network and the amount of radiation. In this context, the grid was modelled in Matlab/Simulink environment to see the system performance. Three different scenarios were performed in order to measure the response of the modelled system for different conditions. In the first scenario, an inductive grid was created and the condition where the grid voltage was not critical, was modelled. Accordingly, it was seen that the inverter contributes to the voltage adjustment by giving a capacitive response to the grid. In the second scenario; the grid was again considered inductively and the radiation amount was modelled to be high. However, with the assumption that voltage had a critical value, the inverter acted fully capacitive and it didn't generate active power to prevent grid voltage drop. In the last case; the grid was thought as capacitive and it was assumed that there is a certain amount of radiation in the environment. In this condition, it was seen that as the system voltage was not critical, the inverter contributes to the grid by generating active power up to the amount of radiation and generating inductive reactive power with its remaining power capacity.

As a result, it was understood, that reactive power generated in electrical grids can be eliminated by means of solar inverters and stable voltage regulation could be achieved in this way. It can be seen that the power losses can be reduced and the grids which were disabled, due to voltage drops, can continue to function. Eventually, good power quality, with an optimal and steady voltage and frequency supply, can be offered to consumers, through the elimination of the reactive powers in the grid. 


\section{Acknowledgment}

We would like to thank to the Scientific Research Projects Unit of Kahramanmaras Sutcu Imam University, which contributes to doing this study with individual project which named as "Power Quality Improvement by Integration of Solar Systems into the Power Grid" and has 2017/7-202M project number.

\section{References}

[1] Molina-García, Á., Mastromauro, R. A., García-Sánchez, T., et al.: Reactive power flow control for PV inverters voltage support in LV distribution networks. IEEE Transactions On Smart Grid, 2017, 8, (1), pp. 447-546 doi: 10.1109/TSG.2016.2625314

[2] Sadnan, R., Khan, Md. Z. R.: Fast real and reactive power flow control of grid-tie photovoltaic inverter. $9^{\text {th }}$ International Conference on Electrical and Computer Engineering (ICECE), Dhaka, Bangladesh, December 2016, pp. 570-573, doi: 10.1109/ICECE.2016.7853984

[3] Safayet, A., Fajri. P., Husain, I.: Reactive power management for overvoltage prevention at high PV penetration in a low-voltage distribution system. IEEE Transactions On Industry Applications, 2017, 53, (6), pp. 5786-5794, doi: 10.1109/TIA.2017.2741925

[4] Islam, M., Afrin, N., Mekhilef, S.: Efficient single phase transformerless inverter for grid-tied PVG system with reactive power control. IEEE Transactions On Sustainable Energy, 2016, 7, (3), pp. 1205-1215, doi: 10.1109/TSTE.2016.2537365

[5] Wang, L., Yan, R., Saha, T. K.: Voltage management for large scale PV integration into weak distribution systems. IEEE Transactions on Smart Grid, 2018, (9), (5), pp. 4128-4139, doi: 10.1109/TSG.2017.2651030

[6] Kraiczy, M., Stetz, T., Braun, M.: Parallel operation of transformers with on load tap changer and photovoltaic systems with reactive power control. IEEE Transactions on Smart Grid, 2018, 9, (6), pp. 6419-6428, doi: 10.1109/TSG.2017.2712633

[7] Marrekchi, A., Kammmoun, S., Sallem, S., et al.: Sliding mode control of reactive power for three-phase grid-connected photovoltaic system. $6^{\text {th }}$ International Conference on Systems and Control (ICSC), Batna, Algeria, May 2017, pp. 121-126. doi: 10.1109/ICoSC.2017.7958666

[8] Jabr, R. A.: Linear decision rules for control of reactive power by distributed photovoltaic generators. IEEE Transactions on Power Systems, 2018, 33, (2), pp. 2165-2174, doi: 10.1109/TPWRS.2017.2734694

[9] Jafarian, H., Parkhideh, B., Enslin, J., et al.: On reactive power injection control of distributed grid-tied AC-stacked PV inverter architecture. IEEE 
Energy Conversion Congress and Exposition (ECCE), Milwaukee, WI, USA, September 2016, pp. 1-6, doi: 10.1109/ECCE.2016.7855303

[10] Sreekanth, T., Narasamma, N. L., Mishra, M. K.: A high gain grid connected single stage inverter system with reactive power control. IEEE International Conference on Industrial Technology (ICIT), Toronto, ON, Canada, March 2017, pp. 358-363, doi: 10.1109/ICIT.2017.7913257

[11] Liu, L. Y., Gao, J. T., Lo, K. Y.: A reactive power control strategy of the grid-connected inverter for microgrid application. IEEE $3^{\text {rd }}$ International Future Energy Electronics Conference and ECCE Asia (IFEEC - ECCE Asia), Kaohsiung, Taiwan, June 2017, pp. 755-759, doi: 10.1109/IFEEC.2017.7992134

[12] Li, D., Ho, C. N. M., Liu, L., et al.: Reactive power control for single-phase grid-tie inverters using quasi sinusoidal waveform. IEEE Transactions on Sustainable Energy, 2018, 9, (1), pp. 3-11, doi: 10.1109/TSTE.2017.2710340

[13] Anurag, A., Yang, Y., Blaabjerg, F.: Thermal performance and reliability analysis of single-phase PV inverters with reactive power injection outside feed-in operating hours. IEEE Journal of Emerging and Selected Topics in Power Electronics, 2015, 3, (4), pp. 870-880, doi:10.1109/JESTPE.2015.2428432

[14] Liu, J., Li, Y., Liu, F., et al: An improved reactive power control strategy for overvoltage fluctuation of distribution network with high penetration of PVs. 36 ${ }^{\text {th }}$ Chinese Control Conference (CCC), Dalian, China, July 2017, pp. 9321-9325, doi: 10.23919/ChiCC.2017.8028842

[15] Jain, C., Singh, B.: Single-phase single-stage multifunctional grid interfaced solar photo-voltaic system under abnormal grid conditions. IET Generation, Transmission \& Distribution, 2015, 9, (10), pp. 886-894, doi: 10.1049/iet-gtd.2014.0533

[16] Akutsu, H., Hirata, K., Ohori, A., et al.: Decentralized active and reactive power control for PV generation plants using real-time pricing strategy. American Control Conference (ACC), Seattle, WA, USA, May 2017, pp. 2761-2766, doi: 10.23919/ACC.2017.7963369

[17] Zhang, F., Guo, X., Chang, X., et al.: The reactive power voltage control strategy of PV systems in low-voltage string lines. IEEE Manchester PowerTech, Manchester, UK, June 2017, pp. 1-6, doi: 10.1109/PTC.2017.7980995

[18] Pothisoonthorn, S., Ngamroo I., Kunakorn, A.: Power swing and voltage stablization by PV generator with active and reactive power controls. IEEE Manchester PowerTech, Manchester, UK, June 2017, pp. 1-6, doi: 10.1109/PTC.2017.7981073 
[19] Liu, L., Gao J., Lo, K. Y.: A reactive power control strategy of the gridconnected inverter for microgrid application. IEEE $3^{\text {rd }}$ International Future Energy Electronics Conference and ECCE Asia (IFEEC - ECCE Asia), Kaohsiung, Taiwan, June 2017, pp. 755-759, doi: 10.1109/IFEEC.2017.7992134

[20] Zeng, R., Wang Z., Chinthavali, M. S.: Coordinated reactive power control of single-phase grid-connected converter for distributed energy resources integration considering multiple functionality conflicts. IEEE Transportation Electrification Conference and Expo (ITEC), Chicago, IL, USA, June 2017, pp. 747-753, doi: 10.1109/ITEC.2017.7993363

[21] Behera, M. P., Ray1, P. K., Beng, G. H.: Single-phase grid-tied photovoltaic inverter to control active and reactive power with battery energy storage device. IEEE Region 10 Conference (TENCON), Singapore, Singapore, November 2016, pp. 1900-1904, doi: 10.1109/TENCON.2016.7848352

[22] Acikgoz, H., Kececioglu, O. F., Gani, A., et al.: Robust control of shunt active power filter using interval type-2 fuzzy logic controller for power quality improvement. Technical gazette, 2017, 24, Supplement (2), https://doi.org/10.17559/TV-20161213004749

[23] Biel, D., Scherpen, J. M. A.: Passivity-based control of active and reactive power in single phase PV inverters. IEEE $26^{\text {th }}$ International Symposium on Industrial Electronics (ISIE), Edinburgh, UK, June 2017, pp. 999-1004, doi: 10.1109/ISIE.2017.8001382

[24] Pal, D., Bajpai, P.: Active and reactive power control in three phase solar PV inverter using modified IC method. 21 ${ }^{\text {st }}$ Century Energy Needs Materials, Systems and Applications (ICTFCEN), Kharagpur, India, November 2016, pp. 1-6, doi: 10.1109/ICTFCEN.2016.8052727

[25] Sekkeli, M., Tarkan, N.: Development of a novel method for optimal use of a newly designed reactive power control relay. Electrical Power and Energy Systems, 2013, 44, (1), pp 736-742, https://doi.org/10.1016/j.ijepes.2012.08.015

[26] Hassan, F., Critchley, R.: A robust PLL for grid interactive voltage source converters. Proceedings of $14^{\text {th }}$ International Power Electronics and Motion Control Conference EPE-PEMC, Ohrid, Macedonia, September 2010, T229-T2-39, doi: 10.1109/EPEPEMC.2010.5606822

[27] Jalilian, M., Nouri, M., Ahmadi, A., et al.: Pulse width modulation (PWM) signals using spiking neuronal networks. IEEE International Conference on Signal and Image Processing Applications (ICSIPA), Kuching, Malaysia, September 2017, pp. 180-184, doi: 10.1109/ICSIPA.2017.8120602

[28] Gutiérrez, M. J. M., Gonzalez, A. R., Merino, F. V.: Low heating losses by harmonic injection PWM with a frequency modulated triangular carrier. 
International Symposium on Power Electronics, Electrical Drives, Automation and Motion, Ischia, Italy, June 2008, pp. 1398-1401, doi: 10.1109/SPEEDHAM.2008.4581229

[29] Albuquerque, F. L., Moraes, A. J., Guimarães, G. C.: Photovoltaic solar system connected to the electric power grid operating as active power generator and reactive power compensator. Solar Energy, 2010, 84, (7), pp 1310-1317, doi: org/10.1016/j.solener.2010.04.011

[30] Kim, I.: Optimal distributed generation allocation for reactive power control. IET Generation, Transmission \& Distribution, 2017, 11, (6), pp. 1549-1556, doi: 10.1049/iet-gtd.2016.1393 